Research Article

\title{
Preparation and Properties of Soy Protein Isolate/Cotton- Nanocrystalline Cellulose Films
}

\author{
Guoyu Zhao, Chongyin Zhou, and Fangyu Fan \\ Key Laboratory for Forest Resources Conservation and Utilisation in the Southwest Mountains of China, Ministry of Education, \\ and College of Life Sciences, Southwest Forestry University, Kunming, Yunnan 650224, China \\ Correspondence should be addressed to Fangyu Fan; ffy118@163.com
}

Received 22 January 2021; Revised 20 February 2021; Accepted 2 March 2021; Published 8 March 2021

Academic Editor: Huining Xiao

Copyright (c) 2021 Guoyu Zhao et al. This is an open access article distributed under the Creative Commons Attribution License, which permits unrestricted use, distribution, and reproduction in any medium, provided the original work is properly cited.

\begin{abstract}
This study was performed to estimate the effect of the incorporation of different cotton-nanocrystalline cellulose (C-NCC) contents with soy protein isolate (SPI) films. The results indicated that the C-NCC content had no effect on the thickness of the composite films $(0.06 \pm 0.01 \mathrm{~mm})$, and the optical property of the composite films decreased as the C-NCC contents increased. Water vapor, carbon dioxide, and oxygen permeability decreased with the introduction of C-NCC and started to increase when the peak of 7\% CNCC was reached. Water solubility of the SPI/C-NCC films decreased from $44.46 \%$ of the SPI films to $35.36 \%$ of the SPI/C-NCC films with 5\% C-NCC. The tensile strength (TS) of films increased from $4.25 \mathrm{MPa}$ to $6.02 \mathrm{MPa}$ by increasing the C-NCC content from 0 to $7 \%$. Then, the TS decreased as the C-NCC content was further increased. The trend of the elongation at break was opposite to that of the TS. The results from FTIR and DSC indicated that the addition of C-NCC did not change functional groups of the SPI films, and the glass transition temperature shifted toward a higher temperature as the C-NCC content increased. Hence, the addition of C-NCC enhanced the barrier and mechanical properties of the SPI/C-NCC composite films.
\end{abstract}

\section{Introduction}

Edible packaging materials are often used in the field of food preservation and packaging and can prevent biological, chemical, and physical hazards in food circulation and transportation. Thus, these materials play an important role in keeping food stability [1]. The packaging is previously intended to facilitate transportation, and people do not pay attention to food preservation. With the development of science and technology, the impact of nonbiodegradable wastes on the environment is increasingly faced by countries worldwide [2]. The formulation of renewable and environmentfriendly biopolymeric materials is urgently needed $[3,4]$. The preparation of biopolymers has made great progress due to environmental problems, oil restrictions, and rising oil prices $[1,5]$. Nevertheless, biopolymers cannot completely replace petroleum polymers; the former can partially replace the latter [6]. Hence, biopolymers are considered promising materials with the advantages of renewability, degradability, edibility, and biocompatibility, for example, the lyocell fiber
[7] and chitosan/ellagic acid films [1]. Moreover, biopolymers can be used as carriers of preservatives, antioxidants, and other substances to protect and improve food quality [8]. The edible film (packaging material) prepared by using a biopolymer is being developed rapidly because of its biodegradability and potential barrier properties to moisture and gases and reduced environmental pollution caused by the application of traditional plastic packaging [9].

The edible film can be prepared from polysaccharides, proteins, lipids, or a combination of these components. Soy protein isolate (SPI) is a food additive with high nutritional value $[10,11]$, which is often used to produce biodegradable packaging materials [12]. The SPI films are transparent, flexible, and biodegradable and have higher barrier properties to oxygen and oil at low relative humidity $(\mathrm{RH})$ [13-15]. However, the water barrier and mechanical properties of the SPI films are poor, which limited the application of the SPI films [16]. The effective way to elevate the properties of the SPI films is to combine SPI with other substances to prepare the SPI composite film. Polysaccharides $[17,18]$, plasticizers 
[19], and nanomaterials [20] are commonly used as raw materials in the preparation of the SPI composite films and have no impact on the environment.

Nanocrystalline cellulose (NCC) is prepared from natural cellulose. The length and width range from $100 \mathrm{~nm}$ to $500 \mathrm{~nm}$ and $1 \mathrm{~nm}$ to $100 \mathrm{~nm}$, respectively [21]. NCC possesses many merits, such as renewability, biodegradability, eco-friendliness, low cost, low density, and biocompatibility [22]. In addition, the abundant surface hydroxyl groups, large surface-tovolume ratio, and high surface activity of NCC made this material a highly desirable natural nanobuilding block to improve the material properties [23]. The results showed that NCC can enhance the mechanical strength and thermal stability of the composites [24]. Khan et al. [25] found that NCC can improve the barrier and mechanical properties of the chitosan composite film. Bajpai et al. [26] obtained similar results in the properties of the chitosan/microcrystalline cellulose films. Ewulonu et al. [27] reviewed the promising lignin-containing nanocellulose. Therefore, NCC can be extensively applied to enhance the properties of food packaging, which makes it get more and more attention. Some studies have applied NCC to enhance the properties of composite films $[28,29]$.

To the best of the authors' knowledge, the properties of the SPI/cotton-NCC (SPI/C-NCC) film have not been reported. Therefore, in this study, the SPI/C-NCC film was prepared, and its properties were characterized using various techniques.

\section{Experimental}

2.1. Materials. SPI (>90\%) was purchased from Guangya Food Materials Co., Ltd. (Guangzhou, China). C-NCC (average diameter, $6.8 \mathrm{~nm}$; average length, 3000-4000 nm; and NCC content, 1\%) was provided by Guilin Qihong Technology Co., Ltd. (Guilin, China). Glycerol was provided by Guangdong Guanghua Science and Technology Co., Ltd. (Guangdong, China).

2.2. Preparation of the SPI/C-NCC Film. The SPI/C-NCC film was prepared according to the casting technique described by $\mathrm{Su}$ et al. [30], with a slight change. The SPI/CNCC films with different NCC contents $(0 \%, 1 \%, 3 \%, 5 \%$, $7 \%$, and $9 \%$ ) were prepared.

$5 \mathrm{~g}$ of SPI was dissolved in $45 \mathrm{ml}$ of distilled water at $80^{\circ} \mathrm{C}$. Then, $2.5 \mathrm{~g}$ of glycerol was mixed as a plasticizer, and the mixed solution was stirred continuously with $450 \mathrm{rpm}$ for $30 \mathrm{~min}$ at $85^{\circ} \mathrm{C}$. The mixed solution was cooled to the ambient temperature and centrifuged at $6000 \mathrm{rpm}$ for $10 \mathrm{~min}$. In the end, the supernatant was collected.

Then, various masses of C-NCC $(0.0,1.0,3.0,5.0,7.0$, and $9.0 \mathrm{~g})$ were added into $50,49,47,45,43$, and $41 \mathrm{ml}$ of distilled water, respectively. The mixture was ultrasonically dispersed (IID, Xinyi, China) for $60 \mathrm{~min}$ under $570 \mathrm{~W}$. The C-NCC mixed solutions were mixed into the SPI mixed solution. Then, the SPI/C-NCC solutions were dispersed for $3 \mathrm{~min}$ with a high-speed dispersing homogenizer (FJ200-SH, Luxi, China) at $20000 \mathrm{rpm}$ and placed for $15 \mathrm{~min}$. The residual gas in the SPI/C-NCC solutions was removed by an ultrasonic machine for $15 \mathrm{~min}$ under $270 \mathrm{~W}$ after the upper layer of the mixture was removed. Then, $6 \mathrm{~g}$ of the SPI/C-NCC solution was poured into an organic plastic culture dish $(d=90 \mathrm{~mm})$, dried at $32^{\circ} \mathrm{C}$ for $10 \mathrm{~h}$, and cooled to ambient temperature. Before analysis, the dried SPI/C-NCC films were preserved at ambient temperature and 53\% RH for $24 \mathrm{~h}$.

\subsection{Properties}

2.3.1. Thickness. The thickness of films was estimated by a micrometer at five random positions, and the average value of samples was collected [31].

2.3.2. Optical Property. Light transmittance is one of the optical properties of the film. The SPI/C-NCC film was fixed into the test cell of a spectrophotometer (UV-2600, Shimadzu Japan). With the control group as the reference, the optical barrier property of the films was measured at $600 \mathrm{~nm} \mathrm{[32].}$ The measurement was carried out thrice, and the average value was calculated.

2.3.3. Barrier Properties. Barrier properties include the water vapor permeability rate (WVPR), carbon dioxide permeability rate, and oxygen permeability.

The WVPR of the SPI/C-NCC film was measured gravimetrically and adapted by the cup method. The test cup containing $3.0 \mathrm{~g}$ of dehydrated calcium chloride was sealed by the SPI/C-NCC films, and the cup was placed at ambient temperature and 53\% RH. The water vapor transferred through the film and adsorbed by the desiccant is determined by the weight of the test cup. The test cup was measured every $24 \mathrm{~h}$ for $168 \mathrm{~h}$. The WVPR was calculated as follows [33]:

$$
\mathrm{WVPR}=\frac{\Delta m}{A \times t}
$$

where $A$ is the film area $\left(\mathrm{m}^{2}\right), \Delta m$ is the mass of the water vapor penetration within the corresponding time $(\mathrm{g})$ at $24 \mathrm{~h}$, and $t$ is the measuring time (h).

The carbon dioxide permeability rate was measured by the strong base absorption method. The SPI/C-NCC film was fixed on the top of the cup with anhydrous potassium hydroxide, sealed with paraffin, and weighed at 1-day intervals at room temperature. The whole process lasted for 7 days. This parameter was calculated as follows:

$$
Q_{\mathrm{CO}_{2}}=\frac{\Delta m}{A \times d}
$$

where $A$ is the film area $\left(\mathrm{m}^{2}\right), \Delta m$ is the mass of carbon dioxide within the corresponding time (mg), and $d$ is the measuring time (1 day).

The peroxide value (POV) of peanut oil was used to estimate the oxygen permeability of the composite films. The higher the POV was, the higher the oxygen permeability would be. The oxygen permeability of the composite films was reflected via the POV [34]. The POV of peanut oil was determined according to GB 5009.227-2016. The test cup was filled with $3.0 \mathrm{~g}$ of peanut oil, sealed with the film, and preserved at $60^{\circ} \mathrm{C}$ and $53 \% \mathrm{RH}$ for 7 days. The POV of peanut oil was estimated. 
2.3.4. Water Solubility (WS). A modification of a reported method [35] was determined to estimate the WS of the composite films. The films were cut into pieces $\left(50 \times 20 \mathrm{~mm}^{2}\right)$ and subsequently dried at $105^{\circ} \mathrm{C}$ for $24 \mathrm{~h}$. The dried films were weighed and immersed in $300 \mathrm{ml}$ of distilled water for $12 \mathrm{~h}$. The films were taken out and dried at $105^{\circ} \mathrm{C}$ for $24 \mathrm{~h}$ to estimate the final dry mass of the films. The WS was calculated as follows:

$$
\mathrm{WS}=\frac{m_{0}-m_{1}}{m_{0}} \times 100
$$

where $m_{0}$ is the mass of the initial dry films $(\mathrm{g})$, and $m_{1}$ is the mass of the final dry films (g).

2.3.5. Mechanical Properties. The tensile strength (TS) and elongation at break $(E)$ represent mechanical properties that were measured with an auto tensile tester (UTM5105 Sansi, China) in accordance with the ASTM D882-88. The film was cut into $25.4 \times 150 \mathrm{~mm}^{2}$. The measurement was performed at $50 \mathrm{~mm} / \mathrm{min}$ of the crosshead speed. The values of dividing the maximum load by the initial cross-sectional area of the composite films represent the TS [18], while $E$ was calculated as follows [3]:

$$
E=\frac{L-L_{0}}{L_{0}} \times 100,
$$

where $L$ and $L_{0}$ are the length at the moment of rupture and the initial length $(\mathrm{mm})$, respectively.

2.3.6. Fourier Transform Infrared (FTIR) Spectral Analysis. The FTIR spectra of the films were performed via a spectrometer (TENSON 27, Brooke, Germany). A $2.0 \times 2.0 \mathrm{~cm}^{2}$ portion of the film was sandwiched between two $\mathrm{KBr}$ disks. The spectrum was analyzed in the range $4000-500 \mathrm{~cm}^{-1}$ with a resolution of $4 \mathrm{~cm}^{-1}$.

2.3.7. Differential Scanning Calorimetry (DSC) Analysis. The DSC analysis of films was determined using a thermal analysis system (200 F3 Maia, Netzsch, Germany). The samples (5-10 mg) were scanned over the range of $30^{\circ} \mathrm{C}$ to $300^{\circ} \mathrm{C}$ at $10^{\circ} \mathrm{C} / \mathrm{min}$. Nitrogen, as the protective gas, had a flow rate of $20 \mathrm{ml} / \mathrm{min}$.

2.3.8. Statistical Analysis. The statistical analysis of the data was estimated by analysis of variance via the SPSS program. Differences between pairs of means were performed using Duncan's multiple range tests.

\section{Results and Discussion}

3.1. Thickness. The thickness of the composite films with different C-NCC contents is $0.06 \mathrm{~mm}$, except for the composite film with $9 \% \mathrm{C}$-NCC, which is $0.07 \mathrm{~mm}$ thick. Thus, the C-NCC content has no significant effect $(P>0.05)$ on the thickness of the SPI/C-NCC films.

3.2. Optical Property. The optical property affects the application of the composite films on the food surface. This property not only affects the gloss of the food but also the shelf life of the packaged food [36]. Light transmittance is used to assess the compatibility of the blend composite films [37]. The light transmittances of the composite films with different C-NCC contents are shown in Figure 1. At $600 \mathrm{~nm}$, the light transmittance of pure SPI films is $\sim 81.02 \%$. With the increase of the C-NCC content from $1 \%$ to $9 \%$, the light transmittance of the composite film decreases from $80.53 \%$ to $76.89 \%$. The average diameter of the C-NCC is $6.8 \mathrm{~nm}$, and its light scattering is weak. However, when the C-NCC content is increased, the compatibility of the SPI/C-NCC composite films decreases. The separation of the dispersed and continuous phases enhances scattering and reflection, leading to the reduction in light transmittance. In addition, the C-NCC may not be dispersed in the SPI/C-NCC solution [32], which hinders the passage of light. This phenomenon decreases the light transmittance. High light transmittance improves the appearance of packaging products, but these products are easily affected by light, reducing their quality.

3.3. Barrier Properties. The WVPR of the SPI/C-NCC films affects the shelf life of the packaged food, while low WVPR ensures the quality of the packaged food [22, 38]. Figure 2 shows the WVPRs of the SPI/C-NCC films, which show that the SPI/C-NCC exhibited better water vapor barrier performance than the SPI films. Among the six samples, the SPI films show the highest WVPR $\left(8.36 \mathrm{~g} / \mathrm{m}^{2} \cdot \mathrm{h}\right)$. The reason is that the SPI films adsorb water vapor from the environment because of their numerous hydrophilic amino acids. The results show that the WVPR decreases first and then increases as the NCC content increases. The lowest WVPR is obtained $\left(5.49 \mathrm{~g} / \mathrm{m}^{2} \cdot \mathrm{h}\right)$ at $7 \%$ NCC. The WVPR of the composite films is closely related to their properties. When C-NCC is combined with SPI, the hydroxyl groups of C-NCC and the amino groups of SPI form a strong hydrogen bond, which hinders the water vapor from passing through the composite films and reduces the WVPR of the composite films [39]. The hydrogen bond enhances the crosslinking effect of the SPI/C-NCC films, which increases the complexity of the path of the water vapor passing through the composite films. This characteristic decreases the water vapor velocity in the composite films $[25,40,41]$. At $9 \%$ C-NCC, the WVPR of the composite films increases to $7.44 \mathrm{~g} / \mathrm{m}^{2} \cdot \mathrm{h}$. This phenomenon is due to the fact that the hydrogen bond in the composite films exceeds the saturation state because of the addition of excessive C-NCC. This characteristic results in the increase of hydrophilic groups and the WVPR.

One of the purposes of food packaging is to avoid or reduce the gas exchange between the food and its surrounding environment or different food odors. The gas barrier performance of the composite films is related not only to the fresh-keeping of food but also to the deterioration (such as oil rancidity, enzymatic reaction, and Maillard reaction) and the change in the tissue structures during food storage and transportation. Good barrier performance is the key to maintain food stability [42]. Low carbon dioxide and oxygen permeability are very important to maintain food quality. Figure 3 shows that the $Q_{\mathrm{CO} 2}$ and $\mathrm{POV}$ of peanut oil first decrease and then increase as the C-NCC content increases, 


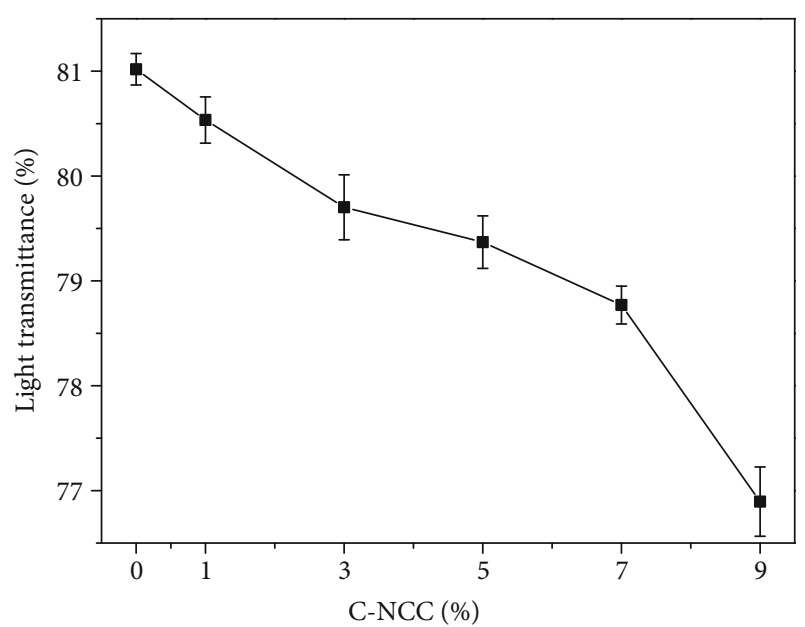

FIGURE 1: Effect of the C-NCC content on the light transmittance of the composite films.

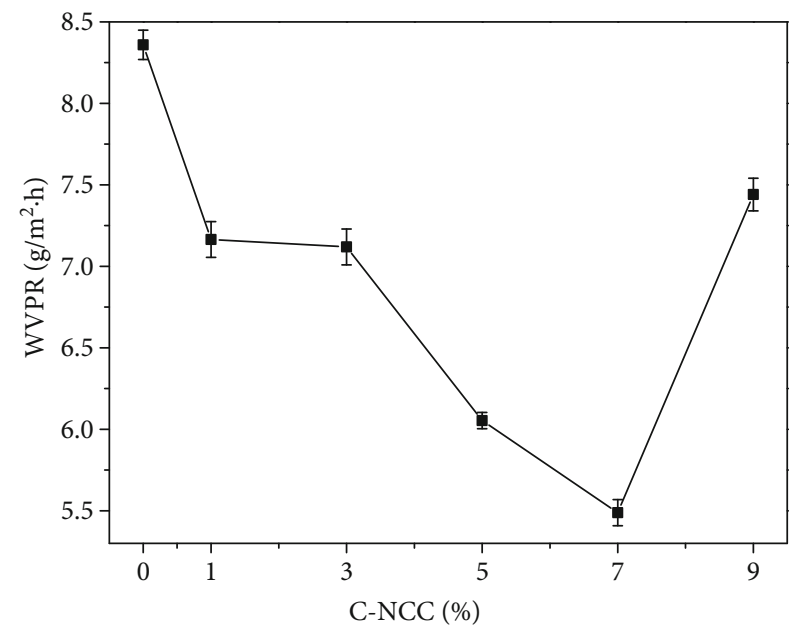

FIgURE 2: Effect of the C-NCC content on the WVPR of composite films.

and the lowest values are obtained at 7\% C-NCC. The SPI films have the highest $Q_{\mathrm{CO} 2}$ and POV among all films. The results show that the addition of C-NCC increases the gas barrier performance of the composite films due to the dense network structure formed by the nanocellulose [43]. When the NCC content exceeded 7\%, the barrier performance decreased. The reason is that the large specific surface area of C-NCC is difficult to disperse in the SPI films, resulting in agglomeration [43]. Thus, the pores of the SPI/NCC films increase, gas permeability is easier, and gas barrier performance is reduced.

3.4. WS Analysis. The WS is an important index to evaluate the durability of composite films in water, which is related to the performance of the materials added to the film [44]. The results show that the presence of C-NCC reduces the WS (Figure 4). The WS values of the SPI/C-NCC films decrease from $44.46 \%$ of the SPI films to $35.36 \%$ of the SPI/C-NCC films with 5\% C-NCC. However, the WS

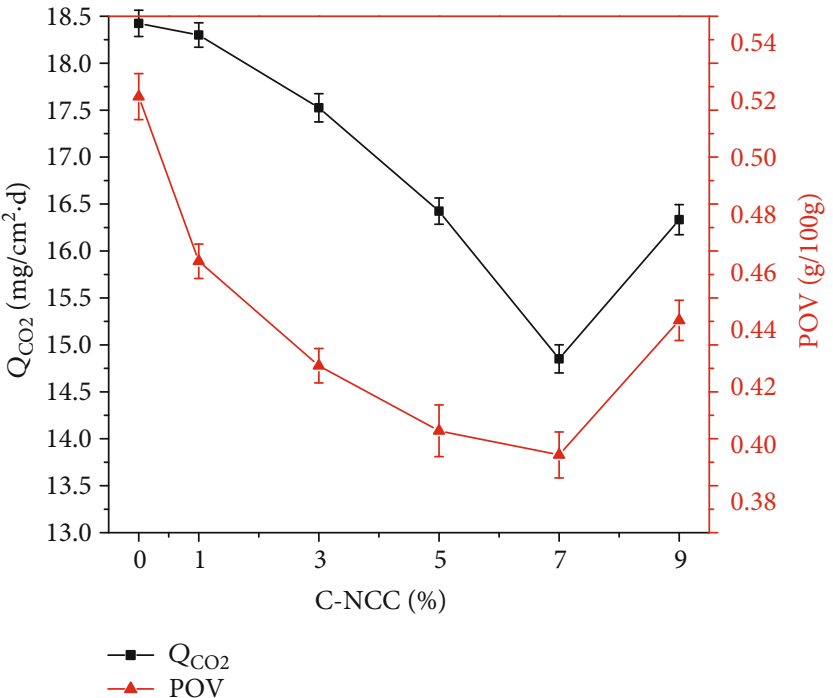

FIgURE 3: Effect of the C-NCC content on the carbon dioxide permeability rate and oxygen permeability of the composite films.

increases with a further increase in C-NCC content. The SPI/C-NCC films reach their maximum water resistance at 5\% C-NCC because the SPI has abundant hydrophilic groups, which leads to good WS of the SPI films (44.46\%). The WS decreases because C-NCC and SPI form a compact network structure, which increases the stability of composite films in water [45]. At 5\% C-NCC, the crosslinking between the two macromolecules reaches its limit, and the WS is no longer reduced.

3.5. Mechanical Properties. Figure 5 shows the mechanical properties of the SPI/C-NCC composite films. These properties are influenced by the content of the C-NCC addition. The TS of the SPI/C-NCC films increases from $4.25 \mathrm{MPa}$ (0\%) to $6.02 \mathrm{MPa}(7 \%)$ with the increase of the C-NCC content and then decreases at higher C-NCC content. However, the TS of the composite films with 9\% C-NCC is still higher than that of the SPI films. This phenomenon may be due to the high surface area of C-NCC, which leads to the strong hydrogen or ionic bonds between C-NCC and SPI [18]. The results are the same as those reported by Reddy and Rhim [46]. However, the reinforcing effect of the CNCC decreases at $9 \%$ C-NCC, probably due to the aggregation of the C-NCC and destruction of the original dense structure of the film matrix. In addition, given the nonuniform stress distribution in the film, the high C-NCC content reduces the interaction between C-NCC and SPI, weakening the strength of the composite films. Contrary to the results of TS, the $E$ of the SPI/C-NCC films decreases with the addition of C-NCC; that is, this parameter decreases from $82.84 \%$ of the SPI films to $45.24 \%$ at $7 \%$ C-NCC and then increases at higher C-NCC content. The reason is that C-NCC can limit the molecular motion of the SPI chains and decrease the flexibility of the films, reducing the $E \%$ of the films.

3.6. FTIR Analysis. The FTIR spectra estimated the functional groups of the films [3]. The functional groups of the 


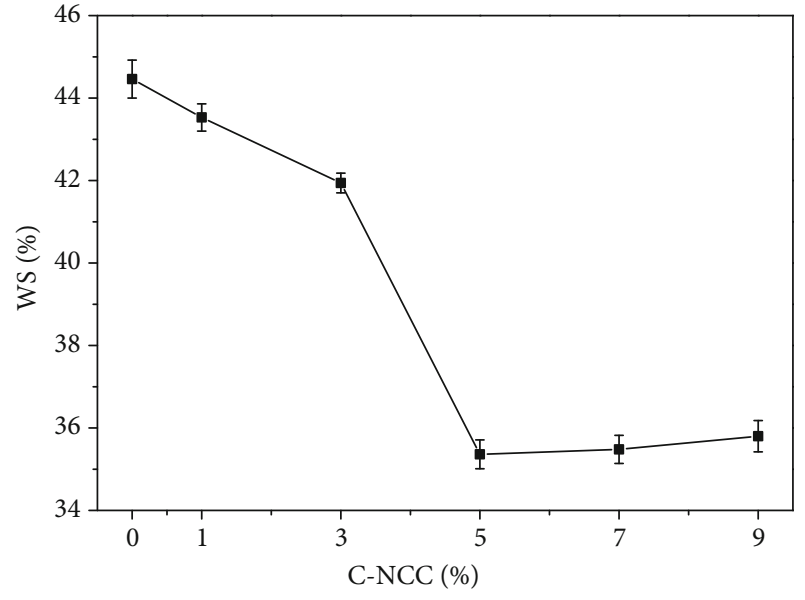

Figure 4: Effect of the C-NCC content on the WS of the composite films.

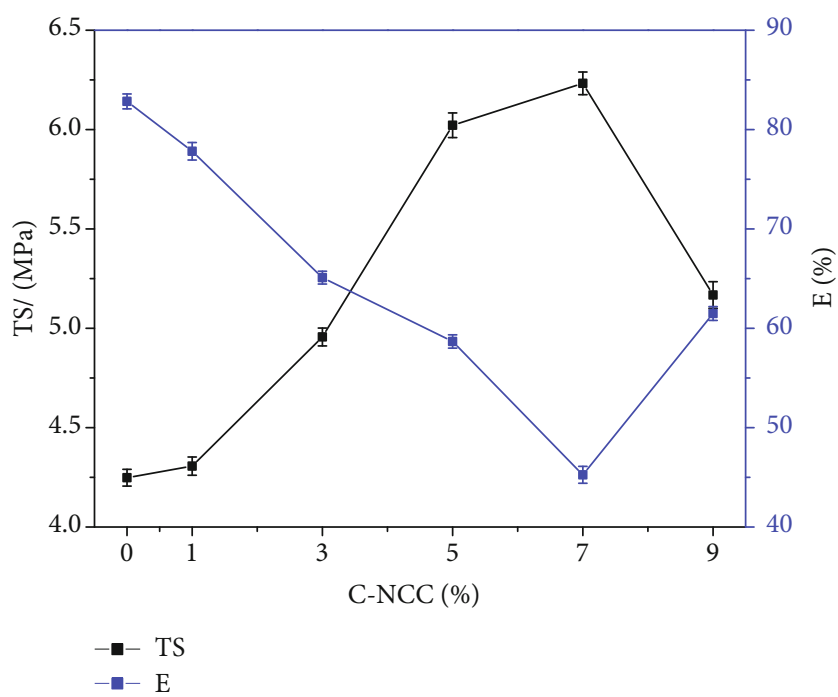

Figure 5: Effect of the C-NCC content on mechanical properties of the composite films.

films are shown in Figure 6. The absorption peak at $3274 \mathrm{~cm}^{-1}$ is attributed to the stretching of the $\mathrm{O}-\mathrm{H}$ and $\mathrm{N}-\mathrm{H}$ groups, which can form a hydrogen bond between C-NCC and SPI [13]. The band at $2936 \mathrm{~cm}^{-1}$ is due to the stretching vibration of the C-H group [46]. Moreover, the main absorption peaks of the SPI films, such as the $\mathrm{C}=\mathrm{O}\left(1628 \mathrm{~cm}^{-1}\right), \mathrm{N}-\mathrm{H}$ $\left(1540 \mathrm{~cm}^{-1}\right)$, and $\mathrm{C}-\mathrm{N}\left(1236 \mathrm{~cm}^{-1}\right)$ stretching, still exist in the SPI/C-NCC composite films [13]. As the C-NCC content increases, the $\mathrm{C}-\mathrm{O}$ stretching vibration peak at $1038 \mathrm{~cm}^{-1}$ in SPI/C-NCC films shows a slight tendency to widen gradually. The SPI and SPI/C-NCC films show similar IR peaks at 4000$500 \mathrm{~cm}^{-1}$, which indicates that the addition of C-NCC does not change the functional groups of the SPI films.

3.7. DSC Analysis. Figure 7 shows the DSC curves of the SPI, C-NCC, and SPI/C-NCC films. According to the DSC curves, the glass transition temperature $\left(T_{\mathrm{g}}\right)$ of SPI and C-NCC is $144.9^{\circ} \mathrm{C}$ and $168.9^{\circ} \mathrm{C}$, respectively. In the SPI/C-NCC films, as the C-NCC content increases, the $T_{\mathrm{g}}$ shifts toward a higher

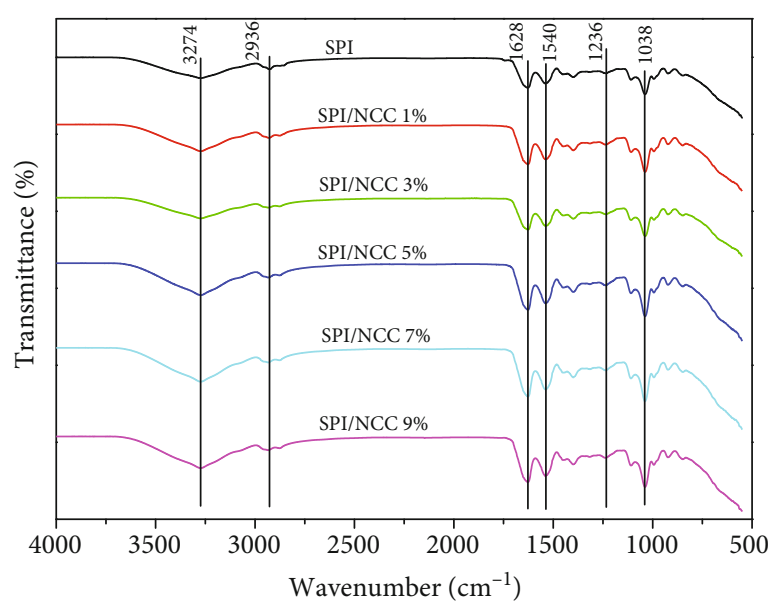

FIgURE 6: Effect of the C-NCC content on the FTIR spectra of the composite films.

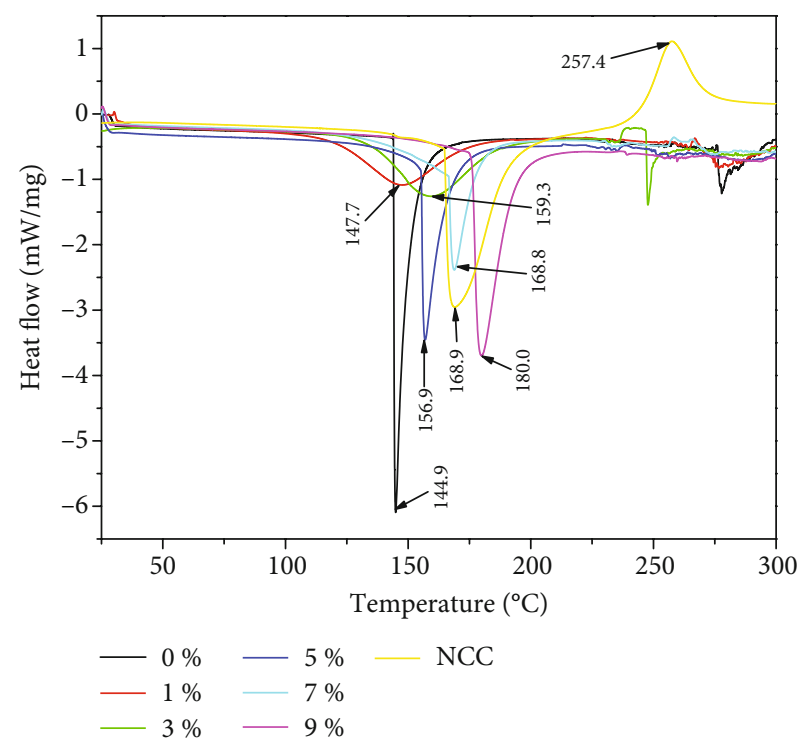

Figure 7: Effect of the C-NCC content on the DSC of the composite films.

temperature. At $1 \%, 3 \%, 5 \%, 7 \%$, and $9 \% \mathrm{C}-\mathrm{NCC}$, the $T_{\mathrm{g}}$ values are $147.7^{\circ} \mathrm{C}, 156.9^{\circ} \mathrm{C}, 159.3^{\circ} \mathrm{C}, 168.8^{\circ} \mathrm{C}$, and $180.0^{\circ} \mathrm{C}$, respectively. The phenomena indicate that the $T_{\mathrm{g}}$ of the composite films is influenced by the C-NCC content because of the interaction between C-NCC and SPI [47]. The strong physical interaction between SPI and C-NCC is possible because of the hydrophilicity of SPI and C-NCC. Moreover, SPI and C-NCC can form the strong hydrogen bonds, which restricts the segmental mobility of the SPI chains, increasing the $T_{\mathrm{g}}$ [48]. $257.4^{\circ} \mathrm{C}$ is the crystal temperature of NCC. In the packaging material, the improvement of thermal stability can protect the storage life of the contents and extend the shelf life.

\section{Conclusions}

The addition of C-NCC can considerably influence the properties of the resulting SPI/C-NCC composite films. The optical property of the composite films decreases as C-NCC 
contents increase. The properties of the composite films, such as the gas barrier property, WS, and mechanical properties, are improved with 7\% C-NCC. The stability of the composite films is also enhanced because of the increase in $T_{\mathrm{g}}$. FTIR spectral analysis indicates that the functional groups of the SPI films are not changed at the addition of C-NCC. Overall, the addition of C-NCC improves the properties of SPI/C-NCC composite films, and these films have a high application prospect in food packaging.

\section{Data Availability}

The data used to support the findings of this study are included within the article.

\section{Conflicts of Interest}

The authors declare that they have no conflicts of interest.

\section{Authors' Contributions}

Guoyu Zhao and Chongyin Zhou contributed equally to this work.

\section{Acknowledgments}

The authors thank the National Natural Science Foundation of China (31760470) and Ten Thousand People Plan of Yunnan Province, Young Top-Notch Personnel (YNWRQNBJ-2018-046).

\section{References}

[1] C. Vilela, R. J. B. Pinto, J. Coelho et al., "Bioactive chitosan/ellagic acid films with UV-light protection for active food packaging," Food Hydrocolloids, vol. 73, pp. 120-128, 2017.

[2] Y. Hu, P. Jia, Q. Shang et al., "Synthesis and application of UVcurable phosphorous-containing acrylated epoxidized soybean oil-based resins," Journal of Bioresources and Bioproducts, vol. 4, no. 3, pp. 183-191, 2019.

[3] C. C. Mohan, K. R. Rakhavan, K. Sudharsan, K. R. Krishnan, S. Babuskin, and M. Sukumar, "Design and characterization of spice fused tamarind starch edible packaging films," $L W T$ Food Science and Technology, vol. 68, pp. 642-652, 2016.

[4] C. Mellinas, A. Valdés, M. Ramos, N. Burgos, M. D. C. Garrigos, and A. Jiménez, "Active edible films: current state and future trends," Journal of Applied Polymer Science, vol. 133, no. 2, pp. 1-15, 2015.

[5] H. Su, P. Zhu, L. Zhang et al., "Waste to wealth: a sustainable and flexible supercapacitor based on office waste paper electrodes," Journal of Electroanalytical Chemistry, vol. 786, pp. 28-34, 2017.

[6] H. Chen, Z. Xu, J. Mo, Y. Lyu, X. Tang, and X. Shen, "Effects of guar gum on adhesion properties of soybean protein isolate onto porcine bones," International Journal of Adhesion and Adhesives, vol. 75, pp. 124-131, 2017.

[7] X. Jiang, Y. Bai, X. Chen, and W. Liu, "A review on raw materials, commercial production and properties of lyocell fiber," Journal of Bioresources and Bioproducts, vol. 5, no. 1, pp. 1625,2020 .
[8] T. Kawasaki, T. Nakaji-Hirabayashi, K. Masuyama, S. Fujita, and H. Kitano, "Complex film of chitosan and carboxymethyl cellulose nanofibers," Colloids and Surfaces B: Biointerfaces, vol. 139, pp. 95-99, 2016.

[9] R. R. Koshy, S. K. Mary, S. Thomas, and L. A. Pothan, "Environment friendly green composites based on soy protein isolate - a review," Food Hydrocolloids, vol. 50, pp. 174-192, 2015.

[10] M. Martelli-Tosi, O. B. G. Assis, N. C. Silva, B. S. Esposto, M. A. Martins, and D. R. Tapia-Blácido, "Chemical treatment and characterization of soybean straw and soybean protein isolate/straw composite films," Carbohydrate Polymers, vol. 157, pp. 512-520, 2017.

[11] L. Ma, B. Li, F. Han, S. Yan, L. Wang, and J. Sun, "Evaluation of the chemical quality traits of soybean seeds, as related to sensory attributes of soymilk," Food Chemistry, vol. 173, pp. 694-701, 2015.

[12] J. Won, J. Lee, D. Jin, and S. G. Lee, “Mechanical properties and biodegradability of the kenaf/soy protein isolate-PVA biocomposites," International Journal of Polymer Science, vol. 10, 11 pages, 2015.

[13] H. Kang, X. Song, Z. Wang, W. Zhang, S. Zhang, and J. Li, "High-performance and fully renewable soy protein isolatebased film from microcrystalline cellulose via bio-inspired poly(dopamine) surface modification," ACS Sustainable Chemistry \& Engineering, vol. 4, no. 8, pp. 4354-4360, 2016.

[14] V. M. Azevedo, M. V. Dias, S. V. Borges et al., "Development of whey protein isolate bio-nanocomposites: effect of montmorillonite and citric acid on structural, thermal, morphological and mechanical properties," Food Hydrocolloids, vol. 48, pp. 179-188, 2015.

[15] P. Oymaci and S. A. Altinkaya, "Improvement of barrier and mechanical properties of whey protein isolate based food packaging films by incorporation of zein nanoparticles as a novel bionanocomposite," Food Hydrocolloids, vol. 54, pp. 19, 2016.

[16] G. A. Denavi, M. Pérez-Mateos, M. C. Añón, P. Montero, A. N. Mauri, and M. C. Gómez-Guillén, "Structural and functional properties of soy protein isolate and cod gelatin blend films," Food Hydrocolloids, vol. 23, no. 8, pp. 2094-2101, 2009.

[17] Z. Qazanfarzadeh and M. Kadivar, "Properties of whey protein isolate nanocomposite films reinforced with nanocellulose isolated from oat husk," International Journal of Biological Macromolecules, vol. 91, pp. 1134-1140, 2016.

[18] S. Shankar and J. W. Rhim, "Preparation of nanocellulose from micro-crystalline cellulose: the effect on the performance and properties of agar-based composite films," Carbohydrate Polymers, vol. 135, pp. 18-26, 2016.

[19] J. Piermaria, A. Bosch, A. Pinotti, O. Yantorno, M. A. Garcia, and A. G. Abraham, "Kefiran films plasticized with sugars and polyols: water vapor barrier and mechanical properties in relation to their microstructure analyzed by ATR/FT- IR spectroscopy," Food Hydrocolloids, vol. 25, no. 5, pp. 12611269, 2011.

[20] F. Shahabi-Ghahfarrokhi, M. M. Khodaiyan, and H. Yousefi, "Preparation of UV-protective kefiran/nano-ZnO nanocomposites: physical and mechanical properties," International Journal of Biological Macromolecules, vol. 72, pp. 41-46, 2015.

[21] E. Csiszar, P. Kalic, A. Kobol, and E. D. P. Ferreira, "The effect of low frequency ultrasound on the production and properties of nanocrystalline cellulose suspensions and films," Ultrasonics Sonochemistry, vol. 31, pp. 473-480, 2016. 
[22] W. Chen, H. Yu, and Y. Liu, "Preparation of millimeter-long cellulose I nanofibers with diameters of 30-80 nm from bamboo fibers," Carbohydrate Polymers, vol. 86, no. 2, pp. 453461, 2011.

[23] S. D. F. Mihindukulasuriya and L. T. Lim, "Nanotechnology development in food packaging: a review," Trends in Food Science \& Technology, vol. 40, no. 2, pp. 149-167, 2014.

[24] F. Jiang and Y. L. Hsieh, "Cellulose nanocrystal isolation from tomato peels and assembled nanofibers," Carbohydrate Polymers, vol. 122, pp. 60-68, 2015.

[25] A. Khan, R. A. Khan, S. Salmieri et al., "Mechanical and barrier properties of nanocrystalline cellulose reinforced chitosan based nanocomposite films," Carbohydrate Polymers, vol. 90, no. 4, pp. 1601-1608, 2012.

[26] S. K. Bajpai, N. Chand, S. Ahuja, and M. K. Roy, "Vapor induced phase inversion technique to prepare chitosan/microcrystalline cellulose composite films: synthesis, characterization and moisture absorption study," Cellulose, vol. 22, no. 6 , pp. 3825-3837, 2015.

[27] C. M. Ewulonu, X. Liu, M. Wu, and H. Yong, "Lignin-containing cellulose nanomaterials: a promising new nanomaterial for numerous applications," Journal of Bioresources and Bioproducts, vol. 4, no. 1, pp. 3-10, 2019.

[28] F. Jiang, T. Kondo, and Y. L. Hsieh, "Rice straw cellulose nanofibrils via aqueous counter collision and differential centrifugation and their self-assembled structures," ACS Sustainable Chemistry \& Engineering, vol. 4, no. 3, pp. 1697-1706, 2015.

[29] M. Jonoobi, R. Oladi, Y. Davoudpour et al., "Different preparation methods and properties of nanostructured cellulose from various natural resources and residues: a review," Cellulose, vol. 22, no. 2, pp. 935-969, 2015.

[30] J. Su, Z. Huang, X. Yuan, X. Wang, and M. Li, "Structure and properties of carboxymethyl cellulose/soy protein isolate blend edible films crosslinked by Maillard reactions," Carbohydrate Polymers, vol. 79, no. 1, pp. 145-153, 2010.

[31] S. F. Hosseini, M. Rezaei, M. Zandi, and F. F. Ghavi, "Preparation and functional properties of fish gelatin-chitosan blend edible films," Food Chemistry, vol. 136, no. 3-4, pp. 14901495, 2013.

[32] J. W. Rhim, S. I. Hong, H. M. Park, and P. K. W. Ng, "Preparation and characterization of chitosan-based nanocomposite films with antimicrobial activity," Journal of Agricultural and Food Chemistry, vol. 54, no. 16, pp. 5814-5822, 2006.

[33] M. Aydinli and M. Tutas, "Water sorption and water vapour permeability properties of polysaccharide (locust bean gum) based edible films," LWT-Food Science and Technology, vol. 33, no. 1, pp. 63-67, 2000.

[34] S. Ou, Y. Wang, S. Tang, C. Huang, and M. G. Jackson, "Role of ferulic acid in preparing edible films from soy protein isolate," Journal of Food Engineering, vol. 70, no. 2, pp. 205210, 2005.

[35] S. Khoshgozaran-Abras, M. H. Azizi, Z. Hamidy, and N. Bagheripoor-Fallah, "Mechanical, physicochemical and color properties of chitosan based-films as a function of _Aloe vera_ gel incorporation," Carbohydrate Polymers, vol. 87, no. 3, pp. 2058-2062, 2012.

[36] M. Hassannia-Kolaee, F. Khodaiyan, R. Pourahmad, and I. Shahabi-Ghahfarrokhi, "Development of ecofriendly bionanocomposite: whey protein isolate/pullulan films with nano$\mathrm{SiO}_{2}$," International Journal of Biological Macromolecules, vol. 86, pp. 139-144, 2016.
[37] M. Pereda, G. Amica, and N. E. Marcovich, "Development and characterization of edible chitosan/olive oil emulsion films," Carbohydrate Polymers, vol. 87, no. 2, pp. 1318-1325, 2012.

[38] Y. Li, H. Chen, Y. Dong, K. Li, L. Li, and J. Li, "Carbon nanoparticles/soy protein isolate bio-films with excellent mechanical and water barrier properties," Industrial Crops and Products, vol. 82, pp. 133-140, 2016.

[39] H. A. Silvério, W. P. Flauzino Neto, N. O. Dantas, and D. Pasquini, "Extraction and characterization of cellulose nanocrystals from corncob for application as reinforcing agent in nanocomposites," Industrial Crops and Products, vol. 44, pp. 427-436, 2013.

[40] J. A. Sirviö, A. Kolehmainen, H. Liimatainen, J. Niinimäki, and O. E. O. Hormi, "Biocomposite cellulose-alginate films: promising packaging materials," Food Chemistry, vol. 151, pp. 343351, 2014.

[41] A. Jensen, L. T. Lim, S. Barbut, and M. Marcone, "Development and characterization of soy protein films incorporated with cellulose fibers using a hot surface casting technique," LWT-Food Science and Technology, vol. 60, no. 1, pp. 162170, 2015.

[42] E. Ayranci and S. Tunc, "A method for the measurement of the oxygen permeability and the development of edible films to reduce the rate of oxidative reactions in fresh foods," Food Chemistry, vol. 80, no. 3, pp. 423-431, 2003.

[43] A. Ferrer, L. Pal, and M. Hubbe, "Nanocellulose in packaging: advances in barrier layer technologies," Industrial Crops and Products, vol. 95, pp. 574-582, 2017.

[44] S. Yin, C. Tang, Q. Wen, and X. Yang, "Properties of cast films from hemp (Cannabis sativaL.) and soy protein isolates. A comparative study," Journal of Agricultural and Food Chemistry, vol. 55, no. 18, pp. 7399-7404, 2007.

[45] A. González and C. I. Alvarez Igarzabal, "Nanocrystal-reinforced soy protein films and their application as active packaging," Food Hydrocolloids, vol. 43, pp. 777-784, 2015.

[46] J. P. Reddy and J. W. Rhim, "Characterization of bionanocomposite films prepared with agar and paper- mulberry pulp nanocellulose," Carbohydrate Polymers, vol. 110, pp. 480488, 2014.

[47] J. Georage and Siddaramaiah, "High performance edible nanocomposite films containing bacterial cellulose nanocrystals," Carbohydrate Polymers, vol. 87, no. 3, pp. 2031-2037, 2012.

[48] C. Li, J. Luo, Z. Qin, H. Chen, Q. Gao, and J. Li, "Mechanical and thermal properties of microcrystalline cellulosereinforced soy protein isolate-gelatin eco-friendly films," RSC Advances, vol. 5, no. 70, pp. 56518-56525, 2015. 